\title{
IIt-Turas
}

website : bit.ly/buletinalturas

\section{Mitos Dan Kritik Lingkungan Dalam Film Aquaman (2018)}

\author{
Okti Ayu Lestari \\ Universitas Islam Negeri Syarif Hidayatullah \\ Jakarta, Indonesia \\ okti.ayu16@mhs.uinjkt.ac.id \\ Reynatania Meydiana Sahara \\ Universitas Islam Negeri Syarif Hidayatullah \\ Jakarta, Indonesia \\ reynatania.meydiana16@mhs.uinjkt.ac.id \\ Zulfa Azza Ardhini \\ Universitas Islam Negeri Syarif Hidayatullah \\ Jakarta, Indonesia \\ zulfa.azza16@mhs.uinjkt.ac.id \\ Inayatul Chusna \\ Universitas Islam Negeri Syarif Hidayatullah \\ Jakarta, Indonesia \\ inayatul.chusna@uinjkt.ac.id
}

\begin{abstract}
Aquaman is a superhero movie that presents the environmental issue through the conflict between human and nature in the middle of the dispute for the throne as the ocean master. The movie also myth related to ocean. This article aims to describe how the movie presents the human-nature relationship. Besides, it also aims to analyze how the myth plays role in improving human-nature relationship. This research uses descriptive qualitative method, ecocriticism approach, and Sonny Keraf's environmental ethical perspective. The result shows the relationship between human and natures that presented in the movie are not harmonious. This unharmonious relationship is shown through the conflict betwen the character of Arthur and Orm, whose each is the representation of human and nature. The research also finds that the myth about the trident influences the formation of environmental ethical perspective. Thus, myth plays an important role in improving the humannature relationship in order to create an ecological balance.
\end{abstract}

Keywords: myth; environmental ethical perspective; ecocriticism; movie analysis

Doi: $10.15408 /$ bat.v26i1.14452 


\begin{abstract}
Abstrak
Penelitian ini bertujuan untuk mengungkapkan hubungan antara lingkungan dengan manusia yang dihadirkan di dalam film Aquaman. Aquaman adalah film superhero yang menghadirkan hubungan problematik antara manusia dan lingkungan di tengah kisah perebutan tahta kerajaan laut. Film ini juga menyajikan mitos yang berhubungan dengan laut sebagai bagian dalam hubungan manusia dan lingkungan. Penelitian ini juga mengkaji bagaimana mitos berperan memperbaiki ketidakharmonisan hubungan antara manusia dan lingkungan. Penelitian ini menggunakan metode deskriptif kualitatif dengan pendekatan ekokritik dan perspektif etika lingkungan Sony Keraf. Hasil dari penelitian ini menunjukkan bahwa hubungan antara alam dengan manusia di dalam film digambarkan tidak harmonis. Hubungan tidak harmonis hadir melalui konflik yang terjadi antara tokoh Arthur dan Orm, yang masing-masing mewakili manusia dan alam. Penelitian ini juga menemukan bahwa mitos mengenai trisula berperan penting dalam membentuk perspektif etik lingkungan yang dihadirkan melalui tokoh Arthur. Dengan demikian, dapat disimpulkan bahwa mitos sangat berperan di dalam memperbaiki hubungan antara alam dan manusia demi menciptakan adanya keseimbangan lingkungan.
\end{abstract}

Kata kunci: mitos; perspektif etik lingkungan; ekokritik; kajian film

\title{
الملخص
}

تهدف هذه الدر اسة إلى الكثف عن العلاقة بين البيئة و البشر في فيلم Aquaman Aquaman. هو فيلم

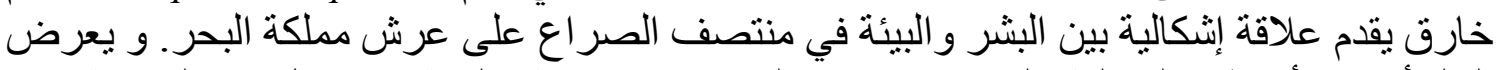

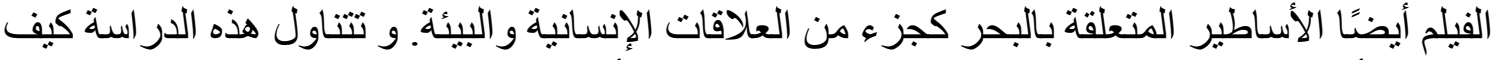

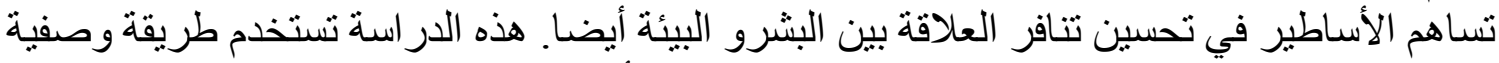

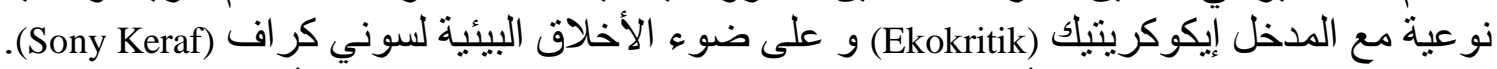

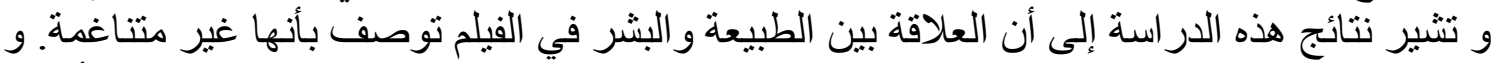

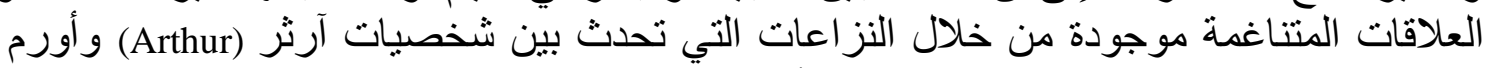

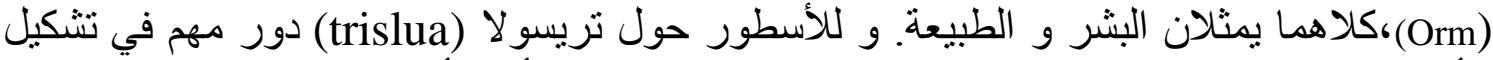

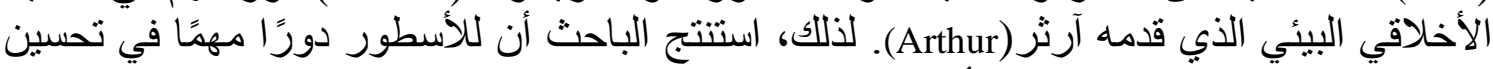

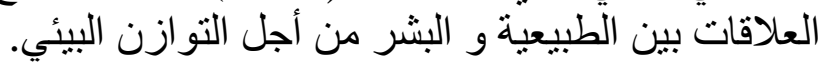

$$
\text { الكلمات الرئيسية: أسطورة؛ الأخلاق البيئية؛ إيكوكريتيك (ekokritik) ؛ در اسات السينما }
$$




\section{PENDAHULUAN}

Dalam kajian sastra, lingkungan merupakan salah satu hal penting dan fenomenal untuk dijadikan sebagai pembahasan. Up dan Devarani dalam tulisannya yang berjudul Dynamics of Ecocriticim menyatakan bahwa lingkungan telah diperlakukan dengan cara yang berbeda dalam kajian sastra dengan berbagai tingkat perkembangan (Up \& Devarani, 2018, p.1383). Hal ini kemudian membuat kritikus menciptakan aliran interdisipliner untuk membahas dan mengkritik karya sastra yang dikenal sebagai ecocriticism. Menurut Glotfelty yang tercantum di dalam jurnal milik Brake dan Corporaal (Bracke \& Corporaal, 2010, p.709) yang berjudul Ecocriticism and English Studies: An Introduction, ekokritik merupakan sebuah studi hubungan manusia dengan alam dalam bidang sastra, film, dan ekspresi budaya lainnya. Ekokritik sendiri mulai berkembang sebagai sebuah kajian sastra pada 1990-an. Cohen (Cohen, 2014, p.10) dalam tulisannya yang berjudul Blues in the Green: Ecocriticism under Critique berpendapat bahwa ekokritik fokus pada bagaimana sastra mengekspresikan pengalamanpengalaman manusia dengan alam. Coupe dalam jurnalnya mengutip pernyataan Burke yang menekankan bahwa keseimbangan hubungan manusia dan alam akan tercapai jika manusia tidak bersikat eksploitatif total terhadap alam (Coupe, 2001, p.413).

Salah satu cara untuk memperbaiki konsepsi ekologi untuk mencegah timbulnya kerusakan berlanjut pada planet ini yaitu dengan mempelajari mitos. Pernyataan Bate yang dikutip di dalam jurnal milik Zekavat menyatakan bahwa mitos merupakan imajinasi yang diperlukan, kisah-kisah teladan yang membantu manusia memahami lingkungannya (Zekavat, 2014a, p.2). Mitos bertahan selama mereka percaya dan melakukan hal yang membantu menjaga alam. Akporobero dalam jurnal yang ditulis oleh Abraham dan Abdulmalik mendefinisikan mitos sebagai jenis cerita atau rangkaian cerita tradisional anonim yang biasanya membahas mengenai budaya tertentu, ada istiadat atau asal usul manusia dan alam secara imajinatif (Abraham and Abdulmalik, p.48). Maka dapat disimpulkan bahwa mitos mungkin diciptakan oleh seseorang untuk membantu menjelaskan peristiwa atau kejadian alam yang saat itu masih misterius dan belum ada ilmu atau pengetahuan yang cukup untuk memahami hal tersebut. Mitos dapat berfungsi lebih dari sebuah cerita belaka, melainkan sebagai bentuk refleksi dari berbagai macam contoh kehidupan manusia yang ada, juga sebagai petunjuk tentang bagaimana cara untuk menjaga hubungan antar masyarakat maupun dengan alam (Wilkinson, p.14). Berdasarkan hal tersebut dapat dikatakan bahwa mitos memiliki kaitan yang cukup erat dalam ekokritik karena banyak sekali mitos-mitos yang menceritakan tentang manusia dan alam serta bagaimana seharusnya manusia berperilaku dengan alam.

Sebagai suatu bentuk produk budaya, keberadaan mitos harus senantiasa dijaga dan dilestarikan. Hal ini dikarenakan di dalam mitos yang berkembang tersebut banyak terkandung nilai-nilai kearifan lokal yang dapat menjadi pengingat manusia untuk dapat bertindak dengan kesadaran demi kebaikan bersama (Purnama et al., 2019, p.722). Menurut (Buell et al., 2011, p.429) di dalam jurnalnya, adanya kearifan lokal di dalam ekokritik juga turut membantu manusia di dalam mempertahankan dan memulihkan kembali keadaan lingkungan yang terjadi akibat dari modernisasi. Kehadiran mitos sebagai bagian dari kearifan lokal sejatinya dapat mempengaruhi banyak perubahan terkait hubungan antara manusia dengan alam. Salah satunya ialah membentuk sifat manusia yang senantiasa menjaga kearifan lingkungan atau etika lingkungan.

Etika lingkungan hidup, menurut Keraf dalam jurnal yang ditulis oleh Sulistijani (Sulistijani, 2018, p.5), merupakan pemahaman kritis tentang apa yang harus dilakukan oleh manusia dalam menghadapi pilihan-pilihan moral mengenai isu lingkungan. Begitu 
pula di dalam karya sastra, pendapat tersebut sejalan dengan pendapat Garrard yang menyatakan bahwa karya sastra berpotensi untuk mengungkapkan gagasan mengenai lingkungan, termasuk nilai-nilai terhadap kearifan lingkungan (Garrard, 2004, p.3). Meneliti kajian berperspekif lingkungan dapat dilakukan dengan difokuskan terhadap kajian perspektif etik yang meliputi sikap hormat terhadap alam, bentuk tanggung jawab terhadap alam, solidaritas terhadap alam, prinsip kasih sayang dan kepedulian terhadap alam, prinsip tidak merugikan alam, prinsip hidup sederhana dan selaras dengan alam, prinsip keadilan, prinsip demokrasi, dan prinsip integritas moral (Keraf, 2010, p.166).

Kajian lingkungan dengan melihat peran cerita-cerita mitos dalam sastra telah dilakukan oleh banyak peneliti. salah satu penelitian ekokritik dengan kajian mitos yaitu penelitian yang dilakukan oleh Zekavat (Zekavat, 2014b) yang meneliti peran mitos asal mula api dalam versi Persia dan Yunani. Zekavat menyimpulkan bahwa mitos diperlukan untuk menata kembali persepsi manusia tentang alam. Penelitian terakhir yang membahas mengenai fungsi mitos dalam kajian ekokritik adalah penelitian yang dilakukan oleh Abraham dan Abdulmalik (Abraham \& Abdulmalik, 2015a) yang meneliti tentang mitos dalam novel Things Fall Apart untuk menjelaskan hubungan antara alam dan budaya manusia dalam Sastra Afrika. Mereka berpendapat bahwa representasi mitos dalam ekokritik dapat berfungsi untuk mengingat kembali hubungan yang harmonis antara manusia dan alam yang hidup saling berdampingan.

Aquaman (2018) adalah film superhero yang mengangkat mitos dunia Atlantis. Film ini menyajikan kisah perebutan tahta antara Aquaman atau Arthur dan Orm untuk menjadi penguasa lautan. Akan tetapi, status Arthur yang memiliki darah campuran dianggap tidak layak karena darah manusia yang dimilikinya. Manusia dengan alam di dalam film pun digambarkan memiliki hubungan yang tidak harmonis. Manusia dianggap sebagai makhluk yang paling bertanggungjawab atas kerusakan yang terjadi di alam, khususnya di lautan. Menariknya, sosok Arthur yang di awal cerita dianggap tidak layak menjadi penguasa lautan pada akhirnya dapat menguasai Trisula Atlan dan mampu menjadi pemilik tahta di Atlantis untuk menyatukan dunia laut dan daratan. Perubahan sikap manusia (Arthur) terhadap alam yang dipengaruhi oleh cerita mitos menunjukkan bahwa film ini menempatkan mitos sebagai bagian penting dalam relasi manusia alam. Argumen tersebut yang akan dibuktikan dalam artikel ini.

\section{METODE}

Penelitian ini menggunakan kritik lingkungan untuk melihat hubungan manusia dan alam yang dihadirkan oleh film Aquaman. Etika kearifan lingkungan yang dijelaskan oleh Sonny Keraf juga digunakan untuk melihat bagaimana mitos berperan dalam perubahan hubungan manusia dan alam. Data dalam penelitian ini adalah film Aquaman (2018) yang meliputi dialog yang diucapkan oleh tokoh. Teknik pengumpulan data yang dilakukan dalam penelitian ini terdiri dari: menonton film Aquaman (2018) secara keseluruhan, mengklasifikasikan data yang ditemukan, melakukan pencatatan serta penandaan terhadap tindakan maupun dialog karakter.

\section{TEMUAN DAN PEMBAHASAN}

\section{Hubungan Manusia dengan Alam dalam Film Aquaman}

Dalam kehidupan, manusia senantiasa bergantung kepada alam untuk memenuhi kebutuhan hidupnya. Akan tetapi, adanya kenyataan bahwa saat ini banyak terjadi permasalahan lingkungan tidak dapat dipungkiri. Permasalahan tersebut muncul akibat 
berbagai faktor, salah satunya ialah disebabkan oleh ulah manusia yang kerap mengganggu alam (Choudhary et al., 2015). Penggambaran hubungan antara manusia dengan alam merupakan sesuatu yang menarik untuk diteliti. Selain itu, penggambaran hubungan keduanya juga dapat ditemui di dalam karya sastra, khususnya di dalam film. Kehadiran tema lingkungan di dalam film nampak menjadi salah satu upaya untuk mengkampanyekan sifat manusia agar lebih menyayangi alam. Oleh karena itu, saat ini tidak jarang para pembuat film memasukkan unsur lingkungan sebagai tema di dalam karyanya.

Kehadiran kajian ekokritik mampu menjadi sarana di dalam melakukan sebuah analisis terhadap interaksi antara karya sastra dengan keadaan lingkungan yang dihadirkan di dalamnya (Buell et al., 2011, p.417). Sebagaimana Glotfelty menyatakan di dalam buku yang ditulis oleh Garrard yang berjudul Ecocriticism, bahwa ekokritik merupakan sebuah ilmu yang mempelajari hubungan antara karya sastra dengan lingkungan, yang menjadikan keadaan bumi sebagai pendekatan di dalam kajiannya (Garrard, 2004, p.3).

Salah satu film yang menarik untuk dikaji dengan menggunakan kajian ekokrtitik ialah film Aquaman (2018). Di dalam film ini, manusia dan alam digambarkan memiliki konflik dan tidak hidup secara harmonis. Hal ini dapat dibuktikan dengan melihat dialog antara Raja Orm dan Raja Nereus dari kerajaan Xebel saat melakukan pertemuan untuk membicarakan Atlantis.

$$
\begin{aligned}
& \text { Raja Nereus : "Violence has always plagued a surface. They will } \\
& \text { destroy themselves" } \\
& \text { Raja Orm : Not before destroying us first." }
\end{aligned}
$$

Percakapan tersebut diambil ketika mereka sedang melakukan pertemuan untuk membicarakan persoalan Atlantis untuk bersatu menghancurkan manusia. Dari percakapan tersebut, terdapat makna yang menyatakan bahwa manusia sering kali melakukan kekerasan, baik itu terhadap sesamanya, maupun terhadap lingkungan disekitarnya. Sifat manusia ini lambat laun akan menghancurkan eksistensi mereka di bumi, karena sifatnya yang gemar merusak dan tidak mau merawat. Di sini, Raja Orm yang merupakan salah satu kaum Atlantis, yang mana ia menghabiskan waktunya di dasar lautan berkata bahwa manusia tidak akan hancur dengan sendirinya sebelum mereka menghancurkan "kita" yang merujuk ke lautan. Kedudukan Raja Orm di sini dapat dikatakan sebagai representasi dari lautan. Manusia di dalam film ini digambarkan sebagai sebuah ancaman terhadap lautan.

Di tengah-tengah pertemuan tersebut, digambarkan bahwa manusia juga melakukan serangan ataupun kerusakan terhadap lautan dengan menggunakan kapal selam berteknologi tinggi yang mereka buat. Pada dasarnya, adanya teknologi dapat digunakan untuk menjaga lingkungan di sekitar manusia ataupun melakukan kerusakan terhadap lingkungan (Allen \& Pisani, 2018). Di dalam konteks ini, teknologi yang diciptakan oleh manusia berada di posisi yang kerap menciptakan kerusakan lingkungan.

Selanjutnya, di dalam film ini juga digambarkan mengenai perilaku manusia yang kerap kali melakukan kerusakan terhadap alam. Keadaan ini turut mendukung adanya alasan mengenai adanya ketidakharmonisan hubungan antara manusia dengan alam. Pernyataan ini didukung dengan perkataan yang dilontarkan oleh Orm kepada Arthur mengenai sifat-sifat kaum permukaan yang kerap merusak alam, khususnya lautan. 
Arthur : "I came here to stop a maniac from destroying the world."

Orm : "I see. And how do you plan to stop he atrocities that the surface continue to commit? Because for a century, they have polluted our waters, and poisoned our children. And now, their skies burn and our ocean boil."

Beradasarkan percakapan di atas, jelas bahwa manusia sebagai makhluk yang hidup di permukaan sering kali melakukan kerusakan terhadap alam. Kerusakan-kerusakan yang disebabkan ini terkadang hanya demi kebaikan manusia semata tanpa melihat efek negatifnya dari sisi lingkungan. Di dalam percakapan tersebut, manusia disalahkan atas berbagai bentuk polusi maupun pencemaran yang terjadi di dunia ini, khususnya atas apa yang terjadi di lautan. Manusia sering mencemari lautan dengan sampah-sampahnya. Teknologi yang diciptakan oleh manusia juga kerap memperburuk keadaan lingkungan. Manusia atas keserakahannya juga turut bertanggungjawab atas eksploitasi yang dilakukan terhadap hasil laut. Oleh karena itu, Arthur sebagai seseorang yang memiliki darah manusia di dalam kejadian tersebut disalahkan atas berbagai kerusakan yang terjadi. Terlebih, kehadiran Arthur yang ingin merebut tahta sebagai Ocean Master atau penguasa lautan untuk menyatukan dunia lautan dengan daratan juga dianggap tidak layak karena dikhawatirkan adanya keberpihakan Arthur kepada manusia yang akan memperburuk keadaan di lautan.

Sifat-sifat Arthur terhadap alam juga memperlihatkan hubungan manusia dan alam. Hal ini dikarenakan, Arthur sering kali mewakili sifat-sifat manusia terhadap alam yang ditunjukkan melalui perbuatan dan perkataannya. Bukti pertama yang berkaitan dengan sifat Arthur terhadap alam ditunjukkan ketika Raja Orm mengirimkan badai besar ke daratan sebagai suatu bentuk ancaman kepada manusia agar tidak semena-mena terhadap alam. Pendapat ini merujuk kepada pernyataan Mera ketika ia menemui Arthur untuk ikut ke Atlantis demi menggagalkan perang antara daratan dan lautan. Di dalam kejadian ini, Mera telah mengingatkan Arthur akan adanya serangan yang dilakukan oleh Orm.

Mera : "Your half-brother King Orm is about to decare war upon the surface world. Billions will die. Your people and mine. We must stop him."

Akan tetapi, pernyataan Mera tersebut ditanggapi dengan sombong oleh Arthur.

Arthur: "It died with my mother. But I promise you this. If Orm attacks, I will treat him exactly the same way your people treated her. With no mercy."

Di dalam percakapan tersebut, sebagai manusia Arthur menunjukkan sisi negatifnya di dalam memperlakukan alam, yakni sifat sombong dan menantang alam. Sebagai makhluk hidup, kesombongan yang terdapat di dalam diri manusia terhadap alam dapat menciptakan relasi yang tidak baik antara keduanya. Hal ini terbukti, terdapat badai besar yang terjadi tak lama setelah percakapan tersebut. Ketika hal tersebut terjadi, Arthur 
sebagai manusia tidak dapat berbuat banyak dan kesombongan tidak akan membantunya untuk memperbaiki hubungan antara manusia dengan alam.

Kesombongan yang dilakukan oleh Arthur juga ditunjukkan ketika ia berhasil ditangkap dan dibawa ke kerajaan Orm karena telah melewati portal pembatas yang mana manusia tidak diperbolehkan masuk ke dalamnya. Ketika Arthur dalam keadaan diborgol bertemu dengan Orm, ia menunjukkan kesombongannya dengan menantang alam dan meremehkan kekuatan Orm sebagai makhluk yang berasal dari lautan.

\section{Arthur: "If you want conflict, why don't you take these chains off, little brother? And we'll see who gets run through."}

Sebagai seorang manusia yang berkekuatan super, Arthur merasa jika segala sesuatu dapat ia kalahkan, begitu pula dengan mengalahkan Orm. Padahal, kedudukan Orm yang berasal dari lautan pada saat ini lebih tinggi dibanding dirinya. Seperti yang telah dijelaskan sebelumnya, kesombongan yang ada di dalam diri manusia terhadap alam menunjukkan suatu bentuk hubungan yang tidak baik antara keduanya. Hal ini dikarenakan, sebagai seorang manusia, seseorang harus menahan kesombongannya demi menjaga alam.

$$
\begin{aligned}
& \text { Orm : "Are you invoking the Combat of the King?" } \\
& \text { Arthur: "Call it whatever you want. I call it an ass-whooping." } \\
& \text { Orm : "Well then. Perhaps that's how we'll proceed." }
\end{aligned}
$$

Seorang manusia juga harus bersifat bijaksana ketika mengambil keputusan, tidak sekedar mengikuti egonya saja. Termasuk ketika berhadapan dengan alam, manusia tidak bisa sembarangan bertindak, karena pada dasarnya alam juga memiliki ketentuan yang harus dipatuhi. Manusia tidak dapat bertindak semena-mena di manapun ia berada, terutama di tempat yang baru ia kunjungi. Percakapan di atas turut menunjukkan hubungan antara manusia dan alam yang tidak bersahabat. Kesombongan dan kecerobohan yang ditunjukkan oleh manusia dapat merusak hubungan keduanya serta mampu memberikan dampak yang tidak baik kepada manusianya itu sendiri.

\section{Mitos Atlantis dan Trisula}

Selama berabad-abad, Atlantis telah menjadi salah satu legenda favorit dunia, sebuah cerita perpaduan antara fantasi dan misteri yang menarik. Atlantis sendiri merupakan sebuah kota legendaris yang digambarkan di dalam karya filsuf Yunani Plato sekitar 429347 tahun sebelum Masehi. Atlantis digambarkan sebagai kota dengan peradaban yang luar biasa kaya dan maju namun kota tersebut hilang tersapu oleh lautan. Tetapi sebenarnya masih belum ada bukti yang jelas mengenai keberadaan Atlantis sesungguhnya. Satu-satunya karya yang memuat mengenai kisah Atlantis adalah hanya karya milik Plato saja. Oleh karena itu, keberadaan Atantis masih sering dipertanyakan hingga saat ini (Cartwright, 2016).

Tanah Atlantis merupakan tanah yang subur serta berlimpah oleh berbagai macam jenis tanaman dan juga logam serta dihuni oleh banyak hewan termasuk gajah. Orangorang Atlantis hidup dengan sejahtera, mereka memelihara hewan, mengairi tanaman mereka, serta membangun kota-kota yang canggih. Selain itu terdapat juga pelabuhan, 
jembatan dan kanal yang indah. Pulau tersebut dikelilingi oleh gunung-gunung serta cincin-cincin laut yang diciptakan oleh Poseidon untuk melindungi rakyatnya. Seluruh kompleks itu juga dikelilingi oleh dinding emas murni dan dihiasi oleh berbagai macam patung yang terbuat dari emas. Kota Atlantis juga digambarkan memiliki air mancur panas dan dingin, pemandian, lintasan balap kuda serta armada besar kapal perang. Atlantis juga memiliki populasi penduduk yang besar serta tentara yang banyak. Plato menyebutkan bahwa Atlantis menggunakan trisula (trident) sebagai senjata mereka (Moe, n.d.).

Dalam mitologi barat, trisula merupakan atribut atau sebuah perlengkapan yang dimilki oleh dewa Yunani Poseidon, yang dikenal sebagai dewa laut, badai dan gempa bumi yang kemudian menjadi dewa maritim Romawi, dengan nama Neptunus. Ia memegang kekuasaan atas dunia yang dipersenjatakan dengan sebuah Trisula sebagai lambang kekuasaannya. Dalam etimologi yunani, nama trisula (trident) terbentuk dari kata tri yang berarti tiga dan dent (dens) yang berarti gigi. Dalam bahasa inggris modern kata dent sendiri juga merupakan kependekan dari dentist (dokter gigi) jadi dapat disimpulkan bahwa trisula (trident) berarti memilki tiga gigi atau cabang (Beer, p.285).

Menurut Beer (Beer, 1999, p.285) bentuk trisula yang bercabang tiga juga memiliki arti tersendiri. Angka tiga dalam mitos yunani melambangkan kekuatan serta merepresentasikan trinity, unity, oposisi awal, tengah, dan akhir. Simbol tersebut juga dapat melambangkan pembagian waktu di dunia yaitu pagi, siang, dan malam serta masa lalu, masa sekarang, dan masa depan. Cabang tiga dalam trisula juga melambangkan kekuasaan Neptunus yang menguasai bumi, surga, dan neraka. Menurut mitos, kekuatan Trisula yang dimiliki oleh Poseidon (Neptunus) dapat menyebabkan gempa bumi dan banjir di negara-negara Asia khususnya India. Setelah Raja Alexander menaklukkan negara-negara tersebut para ilmuan mulai menemukan lambang trisula yang kemudian menjadi simbol dari agama Buddha dan juga dewa Siwa Hindu dan trisula dapat ditemukan di berbagai kuil di India.

Di dalam film Aquaman (2019) dihadirkan mitos mengenai Atlantis dan juga trisula. Di dalam film, Arthur tidak percaya dengan keberadaan Trisula milik raja Atlan yang menurut legenda bisa mengendalikan dunia permukaan dan juga bawah laut.

Hal ini dapat dibuktikan dengan dialog yang diucapkan oleh Ratu Atlanna yang tidak lain merupakan putri dari penguasa lautan dan raja Atlantis yaitu, Raja Atlan. Dalam percakapan ini, Ratu Atlanna menceritakan dongeng kepada Arthur kecil tentang keberadaan mitos Trisula Atlantis.

Queen Atlanna: And the trident would only be wielded by the strongest Atlantean. And it gave king Atlan mastery over the seven seas. It made him so powerful that the ocean itself became jealous, and sent aterrible earthquake to destroy Atlantis down it fell, to the bottom of the ocean. But, legend has it that one day a new king will come who will use the power of the trident to put Atlantis back together again.

$(00: 05: 38)$

Selain itu, mitos terkait Atlantis juga digambarkan dalam film ini melalui percakapan Arthur dengan Putri Y'Mera Xebella Challa, yaitu putri dari Raja Nereus dari Kerajaan Xebel ketika Mera menghampiri Arthur ke daratan untuk memberitahunya perihal peperangan yang akan terjadi antara manusia dengan alam. Namun, Arthur tidak 
mempercayai hal itu, bahkan ketika Mera menyebut soal Trisula, Arthur pun tidak percaya begitu saja.

Mera : But Vulko seems to belief in you for some reasons and that's why I'm here. Vulko has learned the location of the Lost Trident of Atlan.

Arthur : Fairy tales. It's a myth.

Kemudian, pada scene selanjutnya, setelah kejadian tsunami yang terjadi di daratan, banyak stasiun televisi mulai memberitakan hal ini. Tsunami yang terjadi menyebabkan sampah-sampah yang ada di lautan seakan dikembalikan lagi ke daratan. Berita terkait tsunami yang menimpa seluruh kawasan daratan menjadi topik perbincangan hangat di antara manusia, salah satunya terjadi di salah satu stasiun televisi yang mewawancarai seseorang yang percaya akan mitos adanya Atlantis. Namun, para reporter tidak percaya akan keberadaan Atlantis dan hanya menganggapnya sebagai mitos dan teori akan dongeng yang aneh.

$\begin{array}{ll}\text { Reporter } 1 & \text { : Many are asking the question, as this a natural } \\ \text { disaster or something else? } & \\ \text { Dr. Stephen Shin } & \text { : No. No. No. This was no natural disaster. They } \\ & \text { threw out our garbage and our warships. This was } \\ \text { Reporter } 2 & \text { : there you go again with your insane Atlantean } \\ \text { theory. } & \\ \text { Reporter } 1 & \text { :You have absolutely no proof, Dr. Shin. } \\ \text { Dr. Stephen Shin } & \text { :Open your eyes. We already have an Atlantean } \\ & \text { living among us, and his name is Aquaman. }\end{array}$

$(00: 37: 22)$

Kemudian, hal lain terkait mitos trisula terbukti saat Vulko menunjukan gambar mengenai trisula milik Raja Atlan pada Arthur. Pada scene ini, Arthur masih menganggap bahwa trisula hanyalah mitos belaka karena Ia sudah seringkali mendengar cerita tentang trisula yang hilang milik Raja Atlan itu. Namun, Vulko menjelaskan setiap kejadian tentang trisula itu dan bagaimana akhirnya trisula itu menghilang bersama dengan runtuhnya kerajaan Atlantis.

Arthur: I already got one of these.

Volko : Not like this one, this is the Lost Trident of Atlan.

Arthur: I know the story.

Vulko : It's more than a story. It's real. It was forged by the greatest weapon masters in history. Crafted from Poseidon's steel for King Atlan, the first ruler of Atlantis. Legend says the trident was imbued with the power to command the sea.

Arthur: So what happened to it?

Vulko : to know that is to going back to the time befor the Great Fall, when King Atlan rulled overall that was when the kingdoms of Atlantis were one. It was a time of great prosperity and technological advancement. we had unlocked the secret of 
unlimited energy at a time when the rest of the world still thought the earth was flat. But we became too ambitious, too hungry for power. The ocean swallowed us, and Atlantis sank. But the very power that collapsed our civilization also paved the way to our future. It gave us the ability to breath underwater. And so, we evolved. Others regressed, became savage. And the king lived out the remainder of his days in self-imposed exile. Neither he nor the trident, were ever seen again.

$(00: 45: 41)$

Arthur menganggap bahwa keberadaan trisula milik raja Atlan hanyalah sebuah cerita belaka dan tidak nyata. Namun Vulko berusaha untuk meyakinkan Arthur bahwa Trisula tersebut nyata dan Ia harus mencarinya demi menjadi raja untuk dapat menyelamatkan dunia bawah laut dan juga permukaan dari serangan Orm.

Dalam perjalanannya menemukan Trisula, Arthur sadar bahwa Trisula bukanlah sekedar dongeng dan cerita belaka. Keberadaan Trisula memang benar adanya dan hanya seorang raja sejati yang bisa mengambilnya. Tetapi Arthur merasa tidak layak untuk mendapatkan trisula tersebut karena Ia adalah manusia campuran antara dunia bawah laut dan juga daratan. Di akhir perjalanannya untuk menemukan trisula, Arthur bertemu kembali dengan ibunya yang memintanya untuk menjadi raja demi menyelamatkan kedua dunia.

Setelah Arthur mengetahui tentang keberadan trisula yang dapat menghubungkan serta menyelamatkan dunia permukaan dan juga bawah laut, tekad Arthur semakin kuat untuk menjadi raja. Sikap Arthur yang sebelumnnya cenderung acuh terhadap kehidupan bawah laut kini berubah menjadi lebih baik lagi agar Ia layak untuk mendapatkan trisula Raja Atlan yang hilang itu dan bersaing bersama Orm untuk memperebutkan tahta demi menyelamatkan dua dunia.

\section{Pengaruh Mitos Terhadap Perubahan Sikap Arthur}

Seperti yang sudah dijelaskan sebelumnya bahwa mitos merupakan salah satu cara dalam kajian ekokritik sebagai penyeimbang alam dan memiliki pengaruh besar terhadap hubungan manusia dengan alam. Selain hal itu, mitos juga turut berperan di dalam mempengaruhi perubahan sikap manusia dalam bertindak kepada alam. Begitu pula di dalam film Aquaman (2018) mitos dihadirkan dalam bentuk keberadaan trisula Atlan yang telah lama hilang, yang dipercaya dapat mempersatukan manusia dengan alam. Peran mitos dalam hubungan antara manusia dan alam dalam film ini digambarkan melalui perubahan sikap Arthur yang mewakilkan sikap manusia dalam memperlakukan alam. Dengan mempercayai adanya mitos mengenai keberadaan trisula Atlan yang telah lama hilang, hubungan antara manusia dengan alam yang di awal film digambarkan tidak harmonis, secara perlahan mulai membaik seiring dengan perubahan sikap Arthur yang menjadi lebih baik lagi sesuai dengan perspektif kearifan lingkungan.

Menurut Amrih dalam Sukmawan (Sukmawan, p.7) kearifan lingkungan adalah sebuah kesadaran untuk dapat menjadi bagian dari alam sehingga terbentuk hubungan yang satu dan harmonis antara manusia dengan alam. Istilah kearifan lingkungan kemudian berubah menjadi kearifan lokal dengan pertimbangan bahwa kearifan lingkungan merupakan kajian sikap dan perilaku masyarakat lokal. Kearifan lokal sangat berkaitan erat dengan hubungan antara manusia dengan alam karena segala permasalahan yang terjadi di lingkungan atau alam terjadi karena konflik dalam hubungan anatra 
manusia dan alam itu sendiri. Perilaku manusia yang tidak menunjukkan sifat kearifan lingkungan juga menjadi salah satu masalah rusaknya hubungan antara manusia dan alam.

Mengutip pernyataan Keraf dalam jurnal penelitian yang ditulis oleh Sukmawan. Keraf menjabarkan mengenai prinsip-prinsip kearifan lingkungan diantaranya adalah sikap menghormati alam (respect for nature), sikap bertanggung jawab terhadap alam (respect for nature), sikap kasih sayang serta kepedulian terhadap alam (caring for nature) sikap solidaritas terhadap alam (cosmic solidarity) serta sikap untuk tidak merugikan alam (Sukmawan, p.11).

Di dalam film Aquaman hubungan anatara manusa dan alam di awal film tidaklah harmonis. Manusia sering membaut kerusakan terhadap alam di antaranya adalah membuang sampah di laut. Namun saat Arthur akhirnya menyadari keberadaan mitos trisula dan juga perannya sebagai satu-satunya yang dapat memperbaiki hubungan alam dan manusia. Sikap Arthur mulai menunjukan perubahan. Arthur mulai peduli terhadap alam. Perubahan sikap Arthur tersebut tercermin dari beberapa prinsip kearifan lingkungan diantaranya:

\section{Sikap Hormat Terhadap Alam}

Sikap hormat terhadap alam didasari oleh kesadaran manusia bahwa alam mempunyai hal untuk dihormati karena kehidupan mansuia bergantung pada alam. Jika alam rusak manusia juga akan sulit untuk bertahan hidup. Jadi dapat dikatakan bahwa alam merupakan satu kesatuan yang harus dihormati Contoh sikap hormat terhadap alam diantaranya adalah kesanggupan menghargai alam, kesadaran bahwa alam mmepunyai nilai tersendiri serta kesadaran bahwa alam memilki hak untuk dihormati.

Di dalam film, sikap hormat terhadap alam yang ditunjukkan dalam film Aquaman yaitu dalam bentuk sikap tidak egois dari Arthur yang mengakui bahwa ia tidak begitu layak untuk menjadi penguasa lautan dan ia menyadari bahwa kekuatannya di lautan tidak berfungsi baik di lautan terutama saat ia melawan Orm. Arthur merasa dirinya bukanlah apa-apa jika dibandingkan dengan kekuatan lautan.

Arthur: We should turn back. We can still warn the surface. Try and prepare them for what's coming

Mera : Turn back?

Arthur: Look, i learned from a young age not to show weakness. Okay? I solve my problems with my anger and my fits. I'm a blunt instrument and $i ; m$ damn good at it. But $i$;ve done nothing but get my ass kicked this whole trip. I;m no leader. I;m not a king. I do not work or play well with others and $i$ can't let you die trying to turn me into something that i'm not

Dari percakapan tersebut dapat dilihat bahwa Arthur memiliki sedikit ketidakpercayaan diri setelah semua hal yang terjadi kepada dirinya selama perjalanan mencari trisula yang hilang. Namun, Mera meyakinkan bahwa Arthur layak karena ia memiliki dua campuran darah dan hal itu dapat dijadikan sebagai jembatan untuk menyatukan manusia dan alam. 


\section{Sikap Tanggung Jawab Moral Terhadap Alam}

Hidup manusia sangat bergantung pada alam, oleh karena itu merupakan sebuah kewajiban bagi manusia untuk dapat menjaga dan melindungi alam. Sikap tanggung jawab moral terhadap alam merupakan bentuk usaha atau tindakkan yang dilakukan untuk menjaga alam semesta dan segala isinya. Sikap tanggung jawab terhadap alam dapat terbentuk apabila manusia mulai menyadari bahwa kehidupan alam bukanlah sekedar untuk kehidupan manusia. Alam juag memiliki nilai dan kehidupan sendiri yang perlu dijaga. Maka, dapat dikatakan bahwa kelestarian dan kerusakan yang terjadi pada alam merupakan tanggung jawab bersama seluruh umat manusia.

Sikap tanggung jawab moral terhadap alam yang ada di film Aquaman ini digambarkan oleh keintelektualan Arthur dalam perjalanan menemukan Trisula Raja Atlan yang hilang. Scene pertama yaitu saat Arthur dan Mera menemukan kerajaan gurun yang hilang untuk menemukan petunjuk dari rekaman terakhir Raja Atlan dengan teknologi dari kerajaan gurun tersebut.

Arthur : of course it's not working. It's been sitting here collecting dust since before the Sahara was a desert Man!

Mera : since before the Sahara was desert

Arthur: Thank you for repeating what i just said

Mera : it's completly dried out (SIGH) Let's just say you do your best thinking when you're not thinking at all. All right, now hold still

(01:18:36)

Pada scene tersebut, Arthur memberikan ide yang bagus karena Ia mengungkapkan bahwa mesinnya tidak akan menyala karena sudah lama terpendam di debu. Secara tidak sadar, Ia mememiliki intelektual untuk bisa layak mendapatkan Trisula tersebut dan hal ini merupakan bentuk sikap tanggungjawab moral terhadap alam dengan adanya intelektualitas di dalam diri manusia.

Sikap intelektual Arthur selanjutnya ditunjukkan ketika mereka sampai di Italia untuk menemukan letak Trisula berdasarkan petunjuk dari peta dan rekaman terakhir Raja Atlan.

Arthur: Look in the bottle for the charted path. Hmm oh man

Mera : what?

Arthur: wow (LAUGHING) That's awesome

Mera : Let me see. Wow. But how do you know where to point it?

Arthur: Here, let me see. What was the last line?

Mera ; Only in the hand of the true king can he truly see

Arthur: Only in the hands of the true ..." Marcus Agrippa. He was a great general, but he wasn't a king. Neither was Scipio

Mera : How do you know all this stuff?

Arthur: Because my pops. He made sure i know my history. None of these guys are kings axcept this guy. Romulus. First king of Rome. "Only in the hands of the true king can he truly see" (ARTHUR CLEARS THROAT) (ARTHUR LAUGHING) There it is. That's our heading

$(01: 25: 25)$ 
Dapat dilihat dari percakapan dan scene tersebut bahwa Arthur memiliki pengetahuan yang baik terhadap sejarah-sejarah yang dapat menunjang kelayakannya untuk mendapatkan Trisula Raja Atlan yang hilang tersebut. Arthur berhasil memecahkan teka-teki dari rekaman yang diucapkan oleh Raja Atlan terkait dengan keberadaan trisula yang hilang.

Selanjutnya, Arthur menunjukan sikap tanggung jawab terhadap alam saat Ia akhirnya menyadari bahwa alam dan manusia perlu saling dilindungi dan dijaga satu sama lain. Hal ini terbukti saat Arthur mulai menujukan perubahan sikap untuk menjadi raja. Awalnya Ia tidak ingin menjadi raja karena merasa darah campuran seperti dirinya tidak layak untuk memimpin dunia bawah laut, namun seriring berjalannya cerita, Arthur akhirnya memutuskan untuk menjadi pahlawan bukan hanya sekedar raja. Tapi ia ingin menjadi pahlawan untuk dua dunia, manusia dan alam.

Mera $\quad$ :Atlantis has always had a king. Now, it needs something
Arthur $\quad$ : But what could be gerater than a king?
Queen Atlanna: A hero. A king fights only for his nation. You.. fight for
everyone

Dalam kutipan dialog diatas dapat dikatakan bahwa alasan Arthur menjadi raja bukanlah karena tahta atau kekuasaan semata. Ia bersaing bersama Orm untuk memperebutkan tahta dan berjuang untuk mendapatkan trisula yang hilang demi melindungi dunia daratan dan juga bawah laut karena Arthur sadar bahwa kedua dunia harus saling dilindungi bukan hanya daratan saja. Arthur merasa bertanggung jawab terhadap kehidupan alam dan juga manusia. Jika Arthur tidak memilki sifat ini, mungkin ia akan memilih untuk pergi kembali ke daratan dan tetap pada pendiriannya untuk tidak menjadi raja.

\section{Sikap Solidaritas Terhadap Alam}

Sikap solidaritas terhadap alam berarti ikut merasakan apa yang dirasakan oleh alam atau mahluk hidup lain. Sikap solidaritas ini dapat ditunjukan pada ikut merasa sedih dan prihatin terhadap kepunahan hewan atau kerusakan alam karena manusia dan alam merupakan satu kesatuan. Sikap ini kemudian mendorong manusia untuk menyadari pentingnya menyelamatkan lingkungan hidup dan mengambil segala keputusan untuk mennetang segala perbuatan yang dapat merusak lingkungan hidup. Sikap solidaritas terhadap alam ditandai oleh pengakuan kedudukan setara dan sederajat anatara alam dengan sesama mahluk hidup lain di bumi, sikap turut merasakan apa yang dirasakan oleh alam, serta upaya untuk menjaga keharmonisan hubungan antara alam dan manusia. Sikap ini akan menumbukkan perasaan solidaritas dalam diri manusia bahwa ia merasa sepenanggungan dengan alam dan juga mahluk hidup lain hal ini akan membuat manusia akan mencoba segala cara untuk menyelamatkan alam dan juga mahluk hidup yang lain.

Di dalam film Aquaman, terdapat scene dimana Arthur menyelamatkan Mera dan dirinya dari kejaran Orm dan bangsa Atlantis yang lain karena kabur dari pertempuran Arthur dan Orm. Saat itu Arthur berkomunikasi dengan seekor ikan paus untuk menyembunyikan mereka di dalam perut paus tersebut dan membawa mereka ke tempat tujuan. 


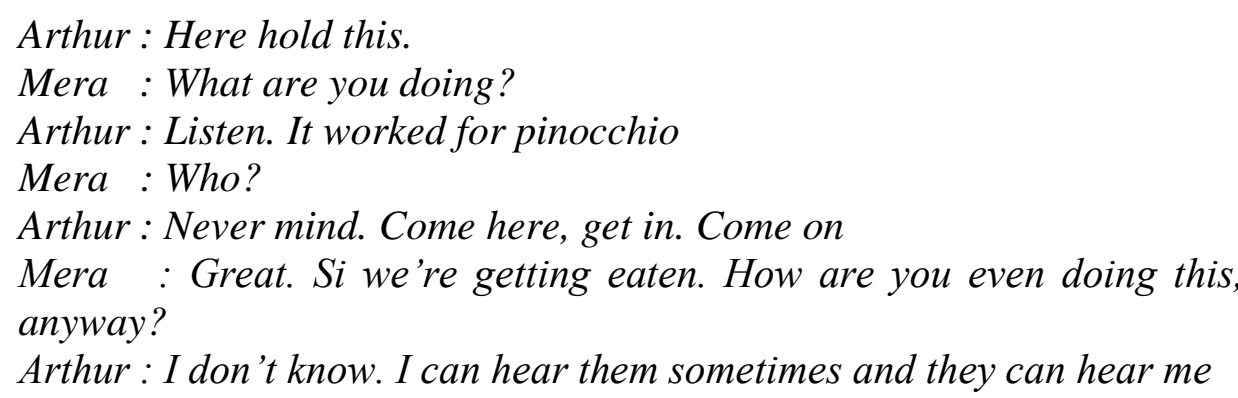

Selanjutnya, Arthur menunjukkan sikap solidaritas terhadap alam dan juga makhluk hidup yang lain terutama manusia terlihat saat Arthur berusaha untuk meyakinkan Karathen, makhluk yang menjaga Trisula milik Raja Atlan tentang maksud kehadirannya di tempat itu untuk mengambil trisula milik Raja Atlan.

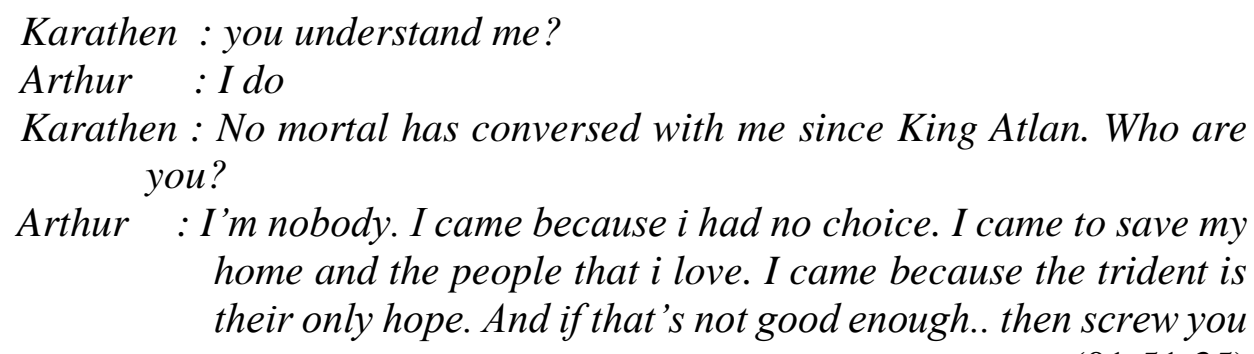

Arthur mencoba untuk meyakinkan Karathen bahwa Ia datang bukan karena ingin memperebutkan tahta dan menjadi penguasa. Ia datang karena Ia tidak punya pilihan lain. Ia ingin menyelamatkan rumahnya di daratan dan juga orang-orang yang Ia sayangi termasuk dengan kehidupan bawah laut. Arthur juga mengatakan bahwa demi menyelamatkan kedua hal tersebut, trisula merupakan satu-satunya jalan. Berdasarkan hal tersebut dapat disimpulkan bahwa Arthur ikut merasakan apa yang dirasakan oleh alam dan mahluk hidup lain. Arthur berjuang untuk mendapatan trisula agar kedua dunia yaitu daratan maupun bawah laut dapat hidup tentram dan jauh dari marabahaya. Jika Arthur tidak memiliki sifat solidaritas terhadap alam, Ia mungkin akan menyerah untuk mendapatkan trsiula karena Ia tidak peduli terhadap alam maupun mahluk hidup lain. Namun Arthur dengan segala cara berjuang untuk mendapatkan Trisula milik Raja Atlan karena dirinya adalah satu-satunya orang yang dapat melakukan hal tersebut. Dari pernyatan tersebut dapat dikatakan bahwa Arthur menunjukan sikap solidaritas terhadap alam dengan bentuk hati yang bersih karena Ia datang mencari trisula bukan untuk kepuasannya sendiri menjadi penguasa melainkan untuk kepentingan dan kebaikan dua dunia, manusia dan alam.

\section{Sikap Kasih Sayang dan Kepedulian Terhadap Alam}

Sikap kasih sayang dan kepedulian terhadap alam dapat terwujud dari kesadaran bahwa alam memilki hak untuk dilindungi, tidak disakiti, dipelihara dan dirawat. Sikap ini menimbulkan keinginan manusia untuk dapat memelihara alam dan melindungi dengan sebaik-baiknya. Menjaga kerukunan antar sesama mahluk hidup termasuk alam merupakan salah satu pwerwujudan dari sikap kasih sayang dan kepedulian terhadap alam 
jika setiap manusia dapat menjaga perilaku terhadap alam maka keselarasan hubungan anatra alam akan terwujud.

Pada film Aquaman, wujud sikap kasih sayang dan kepedulian terhadap alam pada karakter Arthur terlihat dari saat Arthur ingin mengambil senjata trisula yang dijaga oleh mahluk legenda atlantis bernama Karathen. Awalnya Karathen tanpak tidak senang dengan kehadiran Arthur di tempat itu untuk mendapatkan trisula. Karathen berusaha untuk menyingkirkan Arthur dan melawannya saat Arthur beberapa kali mencoba untuk mengambil trisula. Bagi Karathen, Arthur tidak cukup layak untuk mendapatkan trisula milik Raja Atlan. Namun Arthur memilih untuk tidak melawan balik dan justru berusaha untuk berbicara pada Karathen tentang maksud tujuannya berada di sana.
Arthur : Stop! You're right. I am a hald-breed mongrel. But i did not come here because $i$ thought $i$ was worthy. I know i'm not
Karathen : You understand me?
Arthur : I do
Karathen: No mortal has conversed with me since King Atlan

$(01: 51: 45)$

Dalam kutipan dialog antara Karathen dan Arthur dapat disimpulkan bahwa dibandingakn dnegan menggunakan kekerasan Arthur memilih untuk berebicara dan mencoba mengerti Karathen. Hal ini membuat Karathen luluh karena sebelumnnya beberapa orang yang datang ke tempat tersebut hanya demi mendapatkan trsiula namun ini pertama kalinya pada Karathen seseorang mengajaknya bicara dan mencoba mengerti tentang dirinya sejak Raja Atlan pergi. Perilaku Arthur terhadap Karathen ini merupakan perwujudan dari sikap kasih sayang dan kepedulian terhadap alam.

\section{Sikap Tidak Menganggu Kehidupan Alam}

Sikap tidak menganggu kehidupan alam merupakan perwujudan dari sikap tanggung jawab dan solidaritas terhadap alam. Jika manusia ikut merasa bertanggung jawab atas kerusakan lingkungan maka keinginan untuk menjaga dan tidak mengangguk keberlangsungan hidup alam akan timbul dengan sendirinya. Sikap untuk tidak menganggu kehidupan alam dapat terwujud dari kesadaran untuk tidak merugikan alam, pemertahanan eksistensi mahluk hidup di alam, serta membiarkan dan tidak merusak segala hal yang ada di alam.

Di dalam film, sikap tidak mengganggu kehidupan alam terdapat pada scene saat terjadi perompakan di laut oleh orang-orang tidak bertanggungjawab yang dapat membahayakan kehidupan di bawah laut. Saat itu Arthur merusakan kapal selam milik para perompak dan menyelamatkan lautan dari mereka. Ada seorang perompak yang meminta ampun dan meminta bantuan kepada Arthur untuk menyelamatkan ia dan ayahnya namun Arthur menolak dan menyuruhnya untuk meminta ampun kepada lautan.

Pirate : Wait! Help me! He's trapped! You can't leave him like this! Please!

Arthur : You killed innocent people. You ask the sea for mercy.

(00:20:07) 
Perubahan sikap Arthur terhadap alam saat ia mempercayai mitos trisula memperlihatkan pengakuan Arthur terhadap kekuatan alam. Trisula yang tersimpan di dalam lautan merepresentasikan kekuatan laut yang mampu menyimpan kekuatan trisula. Kepercayaan Arthur terhadap kekuatan trisula menciptakan kearifan lingkungan yang mengubah sikap arogan Arthur terhadap alam sehingga ia dapat hidup berdampingan dengan alam.

\section{KESIMPULAN}

Ekokritik telah banyak berperan untuk melihat bagaimana lingkungan dihadirkan di dalam karya sastra. Begitu pula di dalam film Aquaman. Keadaan alam di dalam film ini digambarkan tidak bersahabat dengan manusia. Sifat-sifat manusia yang sering kali merusak dan tidak memperdulikan lingkungan pada dasarnya mampu menimbulkan kemarahan yang ditunjukkan oleh alam. Di dalam film ini, mitos terkait keberadaan Trisula Atlan sangat membantu di dalam memperbaiki hubungan antara alam dengan manusia yang diwakilkan oleh Arthur. Mitos yang dihadirkan di dalam film Aquaman juga berfungsi untuk mempengaruhi perubahan sifat Arthur yang tercermin di dalam perspektif etik lingkungan.

Oleh karena itu, dapat disimpulkan bahwa karya sastra memiliki peran untuk menghadirkan hubungan yang terjadi antara manusia dengan lingkungan di sekitarnya. Selain itu, peran mitos sebagai salah satu bentuk kearifan lokal juga turut mempengaruhi sifat manusia di dalam menjaga alam. Keberadaan karya sastra, khususnya film juga akan membantu meningkatkan kesadaran manusia untuk senantiasa menjaga dan berbuat baik terhadap alam demi terciptanya keharmonisan lingkungan.

\section{REFERENSI}

Abraham, O., \& Abdulmalik, A. (2015). Ecocritical Analysis of Myth in Achebe's Things Fall Apart. IOSR Journal Of Humanities And Social Science Ver. II, 20(6), 4650. https://doi.org/10.9790/0837-20624650

Allen, M., \& Pisani, C. (2018). Technology can either save or destroy nature. https://www.swissinfo.ch/eng/marco-lambertini_-technology-can-either-save-ordestroy-nature-/43848866

Beer, R. (1999). The encyclopedia of Tibetan symbols and motifs. Shambala; Distributed in the United States by Random House.

Bracke, A., \& Corporaal, M. (2010). Ecocriticism and English Studies: An Introduction. Routledge, 9(September 2014), 37-41. https://doi.org/10.1080/0013838X.2010.518038

Buell, L., Heise, U. K., \& Thornbern, K. (2011). Literature and Environment. Annual Review of Environment and Resources, 36, 417-440. https://doi.org/10.1146/annurev-environ-111109-144855

Cartwright, M. (2016, April 8). Atlantis. Ancient History Encyclopedia. https://www.ancient.eu/atlantis/ 
Choudhary, M. P., Chauhan, G. S., \& Kushwah, Y. K. (2015). Environmental degradation: causes, impacts, and mitigation. National Seminar on Recent Advancements in Protection of Environment and Its Management Issues.

Cohen, M. P. (2014). Blues in the Green: Ecocriticism under Critique. Environmental History, 9(1), 9-36. https://doi.org/https://doi.org/10.2307/3985943

Coupe, L. (2000). Bate \& Leavis: an Ecocritical Connection? Green Letters, 2(1), 13-19. https://doi.org/10.1080/14688417.2000.10588968

Garrard, G. (2004). Ecocriticism. Routledge.

Keraf, A. S. (2010). Etika lingkungan hidup. Penerbit Buku Kompas.

Moe. (n.d.). Symbol of the Trident | Gnostic Warrior. Retrieved December 14, 2019, from https://gnosticwarrior.com/trident.html

Purnama, Lembah, G., \& Yunidar. (2019). Ethnic Mythology of Kaili in Palu: An Ecocritic Study. Proceedings of the 28th International Conference on Literature: "Literature as a Source of Wisdom," 11-13, 721-731. https://doi.org/10.24815/.v1i1.14533

Sukmawan, S. (n.d.). Model-Model Kajian Ekokritik Sastra. 2008.

Sulistijani, E. (2018). Kearifan Lokal dalam Kumpulan PuisiKidungCisadaneKarya Rini Intama (Kajian Ekokritik Sastra). NUSA, 13(1), 1-14.

Up, A., \& Devarani, B. (2018). Dynamics of Ecocriticism. International Journal of Academic Research and Development, 3(2), 1383-1385.

Wilkinson, P. \& N. P. (2007). E YE WITNESS companions.

Zekavat, M. (2014a). Ecocriticism and Persian and Greek Myths about the Origin of Fire. CLCWeb: Comparative Literature and Culture, 16(4). https://doi.org/https://doi.org/10.7771/1481-4374.2615

Zekavat, M. (2014b). Ecocriticism and Persian and Greek Myths about the Origin of Fire. CLCWeb: Comparative Literature and Culture, 16(4). https://doi.org/https://doi.org/10.7771/1481-4374.2615 